\title{
Methane Production and Conductive Materials: A Critical Review
}

\author{
Gilberto Martins,*두 Andreia F. Salvador, Luciana Pereira, and M. Madalena Alves \\ Centre of Biological Engineering, University of Minho, Campus de Gualtar, 4710-057 Braga, Portugal
}

Supporting Information

\begin{abstract}
Conductive materials (CM) have been extensively reported to enhance methane production in anaerobic digestion processes. The occurrence of direct interspecies electron transfer (DIET) in microbial communities, as an alternative or complementary to indirect electron transfer (via hydrogen or formate), is the main explanation given to justify the improvement of methane production. Not disregarding that DIET can be promoted in the presence of certain CM, it surely does not explain all the reported observations. In fact, in methanogenic environments DIET was only unequivocally demonstrated in cocultures of Geobacter metallireducens with Methanosaeta harundinacea or Methanosarcina barkeri and frequently Geobacter sp. are not detected in improved methane production driven systems. Furthermore, conductive carbon

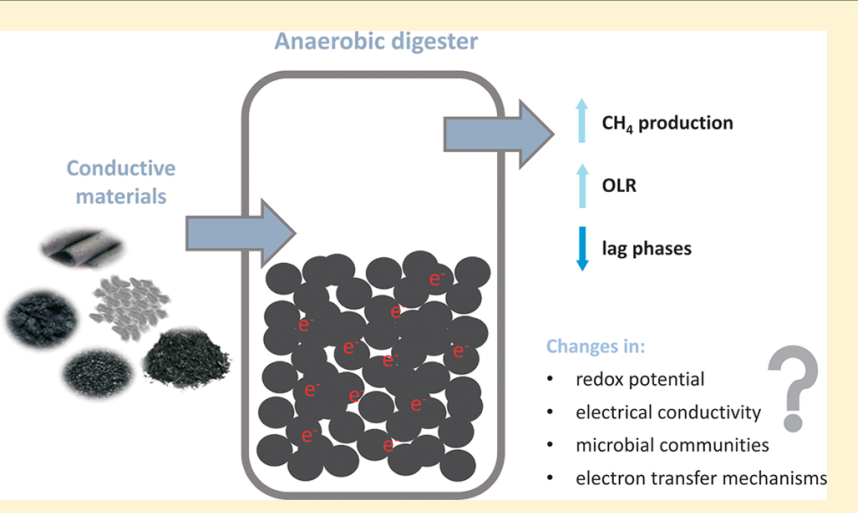
nanotubes were shown to accelerate the activity of methanogens growing in pure cultures, where DIET is not expected to occur, and hydrogenotrophic activity is ubiquitous in full-scale anaerobic digesters treating for example brewery wastewaters, indicating that interspecies hydrogen transfer is an important electron transfer mechanism in those systems. This paper presents an overview of the effect of several iron-based and carbon-based CM in bioengineered systems, focusing on the improvement in methane production and in microbial communities' changes. Control assays, as fundamental elements to support major conclusions in reported experiments, are critically revised and discussed.
\end{abstract}

\section{INTRODUCTION}

Methane is a renewable energy source that can be produced in controlled bioengineered systems from a wide range of organic substrates including diluted industrial wastewater, animal manure or the organic fraction of municipal solid waste, through a process generally called anaerobic digestion (AD). Fundamental knowledge and technology developments of $\mathrm{AD}$ processes have evolved significantly and in parallel in the last decades. The fact that the process relies on the activity of slow growing anaerobic microorganisms ${ }^{1}$ results in low nutrient requirements and low amounts of sludge produced, which are strong advantages of the anaerobic treatment process. These microorganisms grow slowly because the energy gain from the anaerobic metabolism is low and has to be divided by different trophic groups, that is, the bacteria performing hydrolytic, acidogenesis, and acetogenesis reactions, and the methanogens converting intermediary degradation products into methane. ${ }^{2}$

Syntrophic interactions between bacteria and methanogens are the basis to maintain an $\mathrm{AD}$ system working efficiently. These microorganisms, with distinct, but complementary metabolic capabilities, exchange electrons for energy purposes, normally through the transfer of small soluble chemical compounds, such as hydrogen or formate, that act as electron shuttles. This interspecies hydrogen/formate transfer process is very important since the overall thermodynamics depends on the capacity of the microbial communities to maintain a low hydrogen partial pressure. ${ }^{3}$ Thus, diffusion limitations of these metabolites, between anaerobic bacteria and methanogenic archaea, can be important bottlenecks in the anaerobic conversion process. ${ }^{4,5}$

Recent studies proposed that interspecies electron transfer (IET) can also be performed directly between bacteria and methanogenic archaea, or with the aid of conductive materials (CM), being potentially a more energy conserving approach, and thus improving the rate of methanogenesis. 6,7 However, clear evidence of direct interspecies electron transfer (DIET) was only observed in cocultures of electroactive bacteria, namely Geobacter species, and in cocultures of G. metallireducens with Methanosaeta harundinacea $a^{3,7}$ or Methanosarcina barkeri. ${ }^{8}$ Moreover, DIET seems to require outer membrane $c$-type cytochromes and pili, ${ }^{6,7}$ but traditional syntrophic fatty acid-degrading bacteria (e.g., Syntrophomonas wolfei and Syntrophus aciditrophicus) ${ }^{9}$ and most methanogens (e.g., all members of the orders Methanopyrales, Methanococcales, Methanobacteriales and Methanomicrobiales) ${ }^{10}$ lack the genes for these cell components. Another indication that not all syntrophic bacteria are capable of DIET is the case of Pelobacter carbinolicus, a known syntrophic ethanol oxidizing bacterium, that could only establish syntrophic interactions

Received: April 11, 2018

Revised: August 10, 2018

Accepted: August 17, 2018

Published: August 17, 2018 


\section{A: IET via soluble} chemical compounds

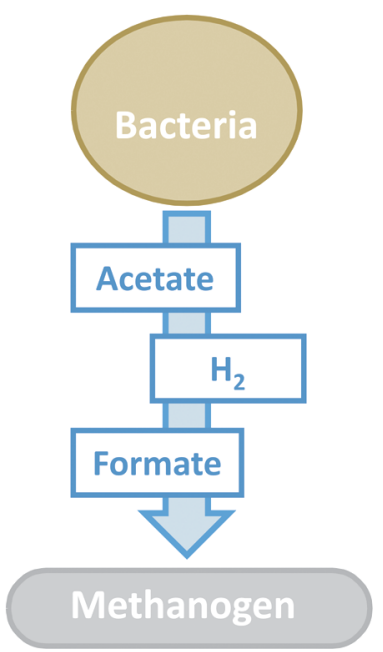

B: IET via extracellular chemical compounds

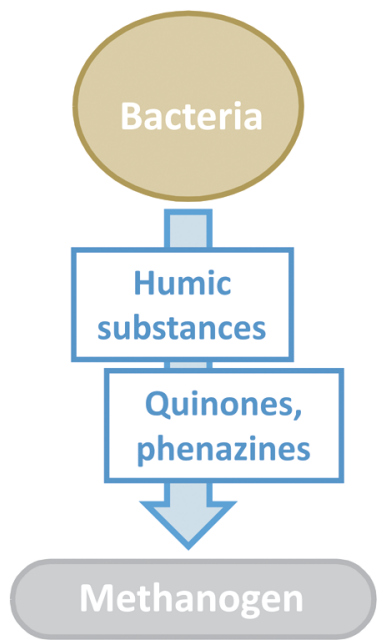

\section{C: DIET via cellular structures}

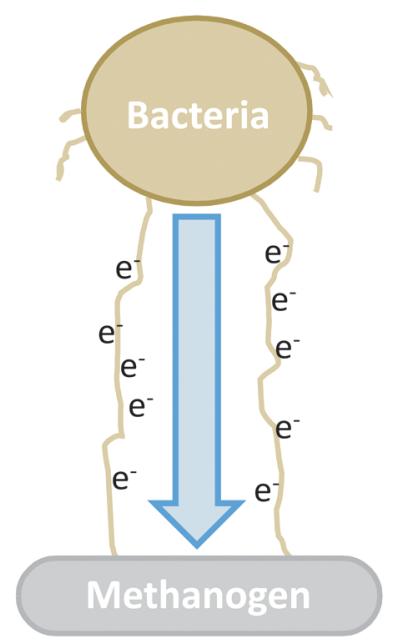

D: DIET via conductive materials

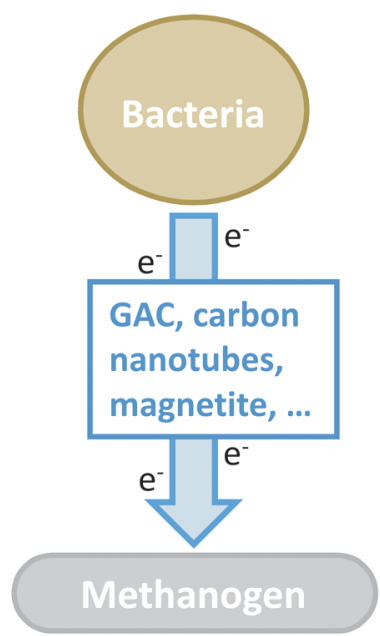

Figure 1. Possible interspecies electron transfer mechanisms in methanogenic environments. ${ }^{42-44}$

with Geobacter sulfurreducens via interspecies hydrogen transfer or interspecies formate transfer, ${ }^{11}$ although it has been reported to contain $c$-type cytochromes. ${ }^{12}$

Notwithstanding these facts, in the past five years, many studies have reported the improvement of methane production in anaerobic reactors amended with $\mathrm{CM}$ such as magnetite, granular activated carbon (GAC), carbon nanotubes (CNT), and biochar, among others. ${ }^{1,8,13-27,}$ In general, these CM are highly stable, have large surface area, good adsorption capacity, and high electric conductivity. ${ }^{28-30}$ Some of these materials may act as redox mediators in microbial catalysis of compounds with electrophilic groups, such as dyes. ${ }^{30}$

The role of DIET is discussed in recent papers on anaerobic digestion processes amended with $\mathrm{CM}^{31-33}$ The authors of these papers interpret the enhancement of methane production as a direct consequence of DIET promoted by CM. However, exploring the results collected from a significant number of studies on this topic, turned clear that the effect of CM goes beyond the stimulation of DIET.

In this review, the recent findings on the effect of $\mathrm{CM}$ in $\mathrm{AD}$ bioengineered systems is summarized, exploring how these materials affect methane production rate and the structure of anaerobic microbial communities. This is a recent research field with a relevant impact in engineered and natural anaerobic microbial processes. Little is known about the mechanisms behind the improvement of methane production rates when CM are present. Apart from DIET, other elements of knowledge should be considered, and main interpretations of the researchers contributing to the knowledge in this field are herein addressed and discussed.

\section{ELECTRON TRANSFER MECHANISMS IN METHANOGENIC ENVIRONMENTS}

Anaerobic digestion is a biological process, where complex organic compounds are sequentially converted to simple compounds, by a wide variety of microorganisms. The rate and the route governing electrons transfer among the microbial community, determines the entire process efficiency. ${ }^{34-37}$ Mineralization of waste to methane is dependent on the activity of hydrolytic, acidogenic, and acetogenic bacteria, which generate the substrates (i.e., hydrogen, formate and acetate) for methanogenic archaea, which ultimately produce methane in $\mathrm{AD}$ processes. ${ }^{37-40}$ IET efficiency between syntrophic partners dictates the rates of conversion bioprocesses when methanogenic activity is guaranteed. In methanogenic systems microorganisms can transfer electrons between each other: (1) via soluble chemical compounds (e.g., hydrogen, formate, and acetate) which act as electron shuttles; (2) via other chemicals (e.g., humic substances); (3) via direct electron transfer by electrically conductive pili or direct contact; and (4) by direct electron transfer mediated by CM (Figure 1). In the following subsections the fundamentals and mechanisms of IET are briefly exposed. ${ }^{33,41-43}$

2.1. Interspecies Electron Transfer via Soluble Molecules. The most studied and well-known mechanism of electron transfer in methanogenic communities is the indirect interspecies electron transfer via hydrogen or formate. ${ }^{9,44-46}$ Syntrophic bacteria produce hydrogen or formate as a way to dissipate the reducing power, i.e., the electrons formed during the degradation of organic compounds and, in turn, methanogens utilize those molecules as electron donors to reduce $\mathrm{CO}_{2}$ to methane (Figure 1A). Therefore, hydrogen/formate act as shuttles between hydrogen/formate-forming bacteria and hydrogen/formate-utilizing methanogens. At high hydrogen concentrations (>10 Pa), the hydrogenase activity is inhibited and consequently the metabolism of syntrophic bacteria is inhibited as well, while that of the methanogens is stimulated, and vice versa. $3,47-49$ Formate formation has been detected particularly in cocultures growing on proteins, ${ }^{50}$ or fatty acids like propionate and butyrate. ${ }^{3,51,52}$ Under certain conditions, interspecies formate transfer may prevail because formate has a higher diffusion coefficient, comparing to hydrogen. ${ }^{53,54}$ Syntrophic interactions involving hydrogen or formate as electron shuttles are well described in cocultures degrading common compounds formed during the $\mathrm{AD}$ process such as butyrate, ${ }^{55}$ propionate, $^{56}$ ethanol, ${ }^{57}$ and acetate. ${ }^{58}$

2.2. Interspecies Electron Transfer via Extracellular Compounds. In numerous anaerobic environments, the interspecies electron transfer can be mediated also by insoluble 
compounds, such as humic acids present in humus. ${ }^{59-62}$ Unlike soluble electron shuttles, such as hydrogen or formate, that can diffuse in and out of the cell, ${ }^{63}$ insoluble compounds do not penetrate the cell surface. Lovley and co-workers ${ }^{64}$ demonstrated that humus can mediate electron transfer between humics-reducing and humics-oxidizing microorganisms (Figure 1B). The electron acceptor properties have been related mainly with the redox active quinone moieties present in humic substances. ${ }^{65}$ Several microorganisms were found to reduce humic acids or anthraquinone-2,6-disulfonate (AQDS) using hydrogen as electron donor (e.g., the halorespiring bacterium, Desulfitobacterium PCE1, the sulfate-reducing bacterium, Desulfovibrio G11 and the methanogenic archaea, Methanospirillum hungatei JF1) or lactate (Desulfitobacterium dehalogenans and Desulfitobacterium PCE1). ${ }^{59}$

Humus can also be reoxidized and act as an electron donor. For example, humic acids can be redox mediators in the anaerobic substrate oxidation coupled to the abiotic reduction of metal oxides such as $\mathrm{Fe}$ (III) and $\mathrm{Mn}(\mathrm{IV})$, being reoxidized and participating in many cycles. ${ }^{59}$ Some bacteria of the genus Geobacter have been reported as quinone-reducing microorganisms using $\mathrm{Fe}(\mathrm{III})$ as the terminal electron acceptor ${ }^{6-69}$ but other microorganisms share this ability, such as some Shewanella, Desulfitobacterium, Desulphuromonas, Geospirillum, Wolinella, and Geothrix ${ }^{69}$ and the methanogenic archaea Methanopyrus kandleri, Methanobacterium thermoautotrophicum. ${ }^{70}$ The anaerobic oxidation of lactate and hydrogen by Desulfitobacterium dehalogenans was obtained with AQDS as mediator, associated with the reduction of goethite. ${ }^{59}$

2.3. Direct Interspecies Electron Transfer. Recently, DIET has been described in anaerobic environments, involving the formation of an electric current between electron-donating

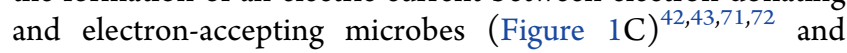
without the need to produce and exchange electron carriers (i.e., hydrogen and formate). DIET is analogous to direct extracellular electron transfer, which consists in the electron transfer between cells and a solid-state electron acceptor such as iron and manganese oxides or electrodes. ${ }^{72}$ Direct extracellular electron transfer is well studied in bacteria belonging to the genera Shewanella and Geobacter, ${ }^{42,43,71}$ which are highly efficient in dealing with solid extracellular electron acceptors. DIET was first described in defined cocultures of $G$. metallireducens, an ethanol oxidizing bacteria, and G. sulfurreducens, a fumarate reducing bacteria. ${ }^{71}$ These microorganisms establish a syntrophic relationship, where $G$. metallireducens metabolize the ethanol and the G. sulfurreducens reduces the fumarate. The ability of this culture for performing DIET was discovered when cocultures formed with $G$. sulfurreducens strains lacking the hyb gene (thus unable to utilize hydrogen), were able to oxidize ethanol and to reduce fumarate. Under these conditions, interspecies electron exchange between G. metallireducens and G. sulfurreducens occurred directly via conductive pili and without the formation of soluble intermediates. ${ }^{71}$ Further, a recent metatranscriptomic analysis showed low abundance of transcripts for hydrogenase and formate dehydrogenase subunits, which provided strong evidence of DIET also between the wildtype of G. metallireducens and G. sulfurreducens. ${ }^{73}$

More recently, it was shown that DIET can occur in cocultures of Geobacter species and acetoclastic methanogens (i.e., Methanosaeta and Methanosarcina species). ${ }^{6,8}$ Rotaru and co-workers ${ }^{6}$ showed that Methanosaeta harundinacea, a strictly acetoclastic methanogen, can receive electrons directly from $G$. metallireducens to produce methane. The idea that Methanosaeta species are acetoclastic specialists, only producing methane from acetate, changed from this point on, since it seems to be able to activate the $\mathrm{CO}_{2}$ reduction pathway for methane production. In this context, the electrons released by Geobacter species are transferred, via pili, directly to Methanosaeta, but the cell machinery involved in electrons uptake by the methanogen is not yet known. ${ }^{6}$ These findings gave a new perspective on the interspecies interactions taking place in anaerobic bioreactors producing methane.

2.4. DIET Promoted by Conductive Materials. The presence of $\mathrm{CM}$ such as $\mathrm{GAC}$, carbon cloth, and biochar appears to promote DIET via a conduction-based mechanism, in which electrons migrate through the $\mathrm{CM}$ from electrondonating to electron-accepting cells. ${ }^{20,22,74}$

Surprisingly, it was observed that the lack of pili and other cell component involved in the exogenous electron transfer can be compensated by the presence of $\mathrm{CM}$, namely GAC, ${ }^{8}$ carbon cloth $^{74}$ and biochar. ${ }^{22}$ This was verified in defined cocultures of pilA-deficient strains of G. metallireducens with Methanosarcina barkeri, which could not convert ethanol to methane unless in the presence of CM. This methanogenic coculture in the presence of biochar were able to utilize $86 \%$ of the electrons released from ethanol oxidation for methane production, but without biochar no ethanol was consumed and no methane was produced. ${ }^{22}$ Similarly, the lack of the pilin-associated c-type cytochrome (OmcS), necessary for extracellular electron transfer in Geobacter species, could be compensated by magnetite, another conductive material. ${ }^{75}$ Without magnetite Geobacter strains lacking genes for OmcS were ineffective in forming viable cocultures, ${ }^{71}$ but in the presence of magnetite, the OmcS-deficient mutants performed similarly to the wild type. ${ }^{75}$

2.5. Hydrogen and Formate IET versus DIET. An interesting approach toward the clarification of the importance of DIET in methanogenesis was presented by Storck and coworkers $^{72}$ who proposed a mechanistic framework that enabled the direct assessment of the relative feasibility of DIET, and mediated interspecies electron transfer (MIET) in a thermodynamically restricted syntrophic system (propionate conversion to acetate and methane), through mathematical modeling. They found that DIET could be more favorable than hydrogen-MIET, but substantially less favorable than formateMIET ( 1 order of magnitude rate difference), assuming a default parameter set based on literature data. The model results also suggested that DIET may be a thermodynamically more feasible alternative to MIET for disperse communities limited by diffusion, which is contrary to experimental observations where nanowire-DIET is commonly observed in dense aggregates, ${ }^{6,8,71}$ possibly indicating that coevolution and cometabolism are more important than external limitations in the simulated system. ${ }^{72}$ These authors also suggested that CM reduce resistivity, and leave only activation losses, making longrange transport even more feasible.

\section{EFFECT OF CONDUCTIVE MATERIALS ON METHANE PRODUCTION}

3.1. CM Improving Methane Production. Several strategies have been implemented to improve $\mathrm{AD}$. Empirical modification of process design, operational conditions, and application of substrate pretreatments, such as microaeration, thermal and mechanical treatments are some examples. $1,76,77$ Recently, several authors have been reporting the enhancement 
Conductive material; Number of studies

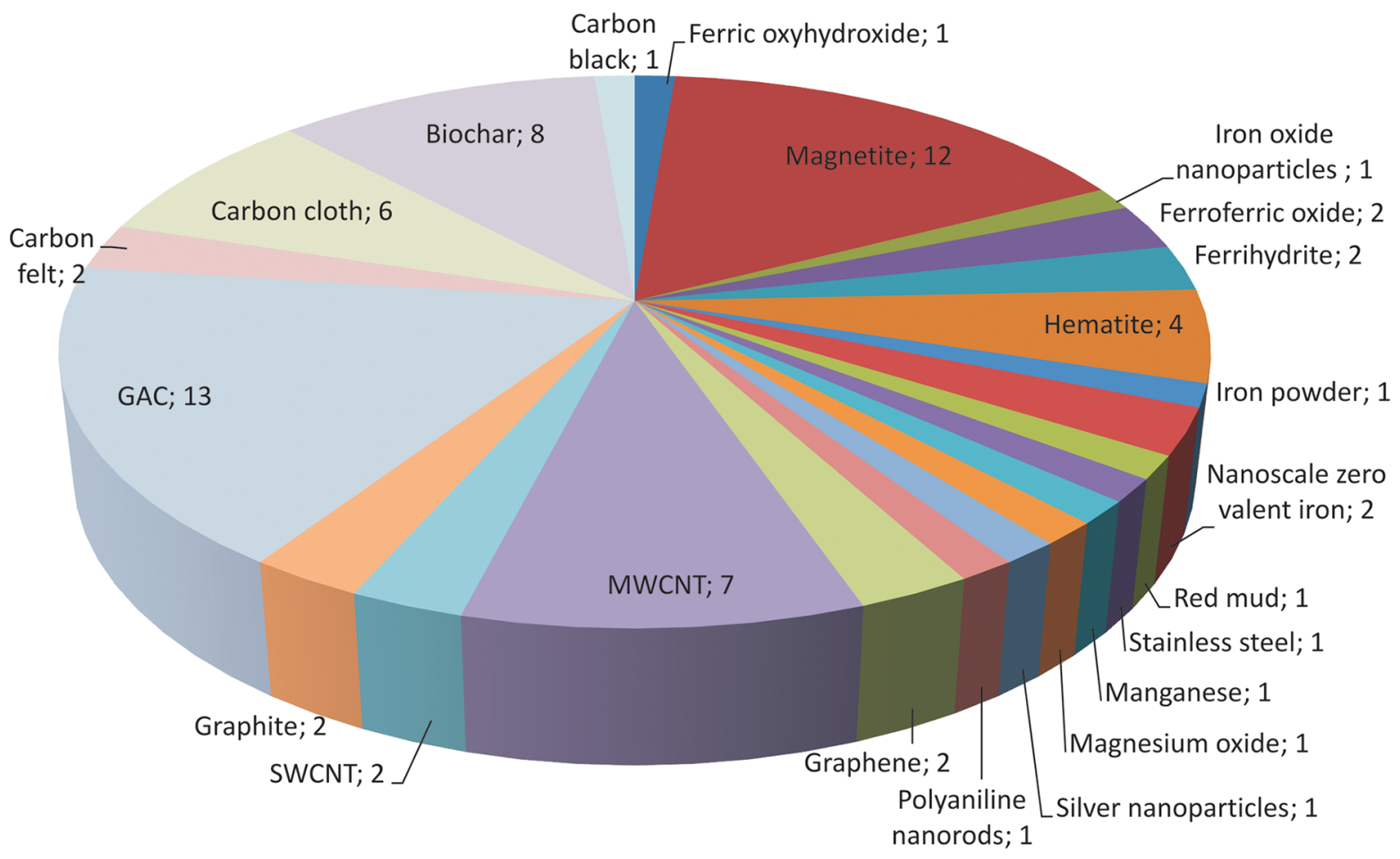

Figure 2. Number of studies reporting the effect of different types of $\mathrm{CM}$ on methane production.

of methane production by the use of CM (Figure 2), which is now considered a strategy to improve methane production efficiency and stability of anaerobic reactors. ${ }^{7,20}$ The type of conductive material, the microbial substrates, the mode of operation and the main results reported in scientific communications are summarized in Table 1 and Supporting Information (SI) Table S1. In general, lag phases preceding methane production are reduced and methane production rates increase when $\mathrm{CM}$ are added to batch experiments. ${ }^{8,16,18-20,27,74,78,79}$ In continuous anaerobic digesters, $\mathrm{CM}$ also accelerate methane production and contribute for a more stable operation, allowing higher applied organic loading rates while maintaining high COD removal rates. ${ }^{21,80-83}$

Only few studies used direct methanogenic substrates, such as acetate or $\mathrm{H}_{2} / \mathrm{CO}_{2},{ }^{18,24,84,85,98}$ while most studies used volatile fatty acids, such as butyrate and propionate, and alcohols as substrates to promote the syntrophic metabolism within microbial communities. $8,16-18,20,22-24,78,79,82,85,96,100$ More complex organic matter, such as dairy wastewater, ${ }^{1,83,86}$ brewery wastewater, ${ }^{20}$ beet sugar wastewater, ${ }^{87}$ food waste, ${ }^{13}$ municipal solid waste, ${ }^{19}$ waste activated sludge ${ }^{89,90,99,103,104}$ or leachate $^{81}$ have also been investigated. When compared to control conditions, the addition of CM to bioreactors treating these complex wastewaters resulted in less accumulation of VFAs, thus improving the efficiency of the $\mathrm{AD}$ process.

GAC and magnetite were the most common CM applied in $\mathrm{AD}$ systems, followed by $\mathrm{CNT}$, carbon cloth and biochar (Figure 2/Table 1).

3.2. CM Inhibiting Methane Production. From all CM tested, magnesium oxide, silver nanoparticles, ferrihydrite and carbon black (amorphous carbon) were the only ones inhibiting methanogenesis (Table 2).

The addition of carbon black nanoparticles $(20 \mathrm{~g} / \mathrm{L})$ to anaerobic sludge completely inhibited methane production from glucose. In these cultures methanogens were more affected than bacteria, and additional pure culture studies showed that Methanosarcina barkeri completely lost activity when growing with carbon black. ${ }^{105}$ The reasons behind the inhibitory effect of carbon black were not investigated but probably due to their small size, they may present antimicrobial properties, similar to those reported for single walled carbon nanotubes. ${ }^{106}$ High concentrations of silver nanoparticles and magnesium oxide (500 mg/g TSS) inhibited methane production from waste activated sludge in $26.5 \%$ and 98.9\% relatively to the control, respectively, although the microbial community composition was apparently not affected. $^{89}$ Both Zhou and co-workers ${ }^{84}$ and Kato and coworkers $^{24}$ reported the inhibition of methanogenesis from acetate and ethanol (0.6-1.9 times comparing with the control) in the presence of ferrihydrite. Indeed, one of the applications of ferrihydrite is specifically the inhibition of methanogenesis, as it was previously reported in several studies. ${ }^{107-112}$ Several reasons have been suggested to justify the inhibition by ferrihydrite: (1) the utilization of the primary electron donors (i.e., acetate or hydrogen) available for methane production by iron reducing bacteria, ${ }^{109,111,113}$ and/ or the diversion of electron flow from $\mathrm{CO}_{2}$ reduction (methanogenesis) to $\mathrm{Fe}(\mathrm{III})$ reduction by methanogens capable of $\mathrm{Fe}$ (III) reduction, ${ }^{114-116}$ thus shifting from methanogenic to iron-reducing conditions, and (2) the increase of the redox potential (to approximately $-100 \mathrm{mV}$ ) caused by the presence of Fe(III) oxides, which does not benefit methanogenic reactions. ${ }^{84,117,118}$ Nevertheless, the secondary iron minerals formed from microbial ferrihydrite reduction, might also benefit methanogenesis. ${ }^{26,119}$ For example, when magnetite is formed as the predominant secondary iron mineral, the methane production rates from acetate and ethanol increased by $30 \%$ and $135 \%$, respectively, 
Table 1. Summary of the Studies Reporting the Enhancement of Methane Production by CM

\begin{tabular}{|c|c|c|c|c|c|}
\hline $\begin{array}{l}\text { conductive } \\
\text { material }\end{array}$ & $\begin{array}{l}\text { particle } \\
\text { size } / \mu \mathrm{m}\end{array}$ & $\begin{array}{l}\text { applied } \\
\text { concentration/ } \\
\mathrm{g} / \mathrm{L}\end{array}$ & common substrates & $\begin{array}{l}\text { methane } \\
\text { improvement }^{a}\end{array}$ & reference \\
\hline $\begin{array}{l}\text { ferric oxyhydr- } \\
\text { oxide }\end{array}$ & 1 to 2 & 1.8 & real dairy wastewater & 2.0 & 1 \\
\hline magnetite & 0.01 to 0.3 & 0.01 to 25 & $\begin{array}{l}\text { acetate, ethanol, benzoate, butyrate, propionate, real and synthetic dairy } \\
\text { wastewater }\end{array}$ & 1.3 to 3.6 & $1,16,17,23-25,27,78,83-86$ \\
\hline $\begin{array}{l}\text { iron oxide } \\
\text { nanoparticles }\end{array}$ & 0.02 & 0.8 & beet sugar industrial wastewater & 1.3 & 87 \\
\hline $\begin{array}{l}\text { ferroferric } \\
\text { oxide }\end{array}$ & 0.01 to 0.3 & 10 & synthetic wastewater & 1.2 to 1.8 & 14,88 \\
\hline ferrihydrite & $\sim 0.03$ & 3.4 to 4.2 & acetate, ethanol & 1.1 & 24 \\
\hline hematite & 0.02 to 0.3 & 0.022 to 10.9 & acetate, ethanol, benzoate, sludge & 1.3 to 2.2 & $24,25,84,89$ \\
\hline iron powder & & 10 & sludge & 1.4 & 90 \\
\hline $\begin{array}{l}\text { nanoscale zer- } \\
\text { ovalent iron }\end{array}$ & $\begin{array}{l}0.001 \text { to } \\
0.1\end{array}$ & 0.02 to 10.9 & sludge & 1.3 to 2.2 & 89,90 \\
\hline red mud & & 20 & activated sludge from municipal wwtp & 1.4 & 91 \\
\hline stainless steel & $\begin{array}{r}500 \text { to } \\
2000\end{array}$ & 25.7 & synthetic wastewater & 1.3 & 92 \\
\hline manganese & 0.07 to 1.5 & 2 to 8 & synthetic wastewater & 4.4 & 93 \\
\hline $\begin{array}{l}\text { polyaniline } \\
\text { nanorods }\end{array}$ & 0.25 to 3 & 1.2 & sucrose & 2.0 & 94 \\
\hline graphene & & 0.03 to 2.0 & ethanol, synthetic wastewater & 1.2 to 1.5 & 95,96 \\
\hline $\begin{array}{l}\text { multiwalled } \\
\text { CNT }\end{array}$ & $\begin{array}{l}0.010 \text { to } \\
0.2\end{array}$ & 0.1 to 5.0 & $\mathrm{H}_{2} / \mathrm{CO}_{2}$, acetate, butyrate, beet sugar industrial wastewater & 1.1 to 17 & $16,18,87$ \\
\hline $\begin{array}{l}\text { single-walled } \\
\text { CNT }\end{array}$ & 0.001 & 1.0 & sucrose, glucose & 1.8 to 2 & 79,97 \\
\hline graphite & 6 to 25 & $\begin{array}{l}12 \text { to } 132 \\
\text { graphite } \\
\text { rods }\end{array}$ & synthetic complex waste and wastewater & 1.0 to 1.3 & 13,80 \\
\hline GAC & $\begin{array}{r}841 \text { to } \\
2000\end{array}$ & 3.3 to 50 & $\begin{array}{l}\text { acetate, ethanol, butyrate, propionate, glucose, synthetic brewery } \\
\text { wastewater, synthetic dairy wastewater, activated sludge, organic } \\
\text { fraction of municipal solid waste, synthetic complex waste }\end{array}$ & 1.1 to 18 & $8,13,15,19-21,79,83,98-100$ \\
\hline $\begin{array}{l}\text { powered acti- } \\
\text { vated carbon }\end{array}$ & 149 to 177 & 5 & synthetic brewery wastewater & na & 21 \\
\hline carbon felt & & 3 to 30 pieces & synthetic wastewater (glucose), and synthetic complex waste & 1.1 & 13,101 \\
\hline carbon cloth & & 10 to 20 pieces & $\begin{array}{l}\text { ethanol, synthetic wastewater, leachate from municipal solid waste } \\
\text { incineration, organic fraction of municipal solid, waste, synthetic } \\
\text { complex waste }\end{array}$ & 1.1 to 10 & $13,19,74,80,81,102$ \\
\hline biochar & 60 to 700 & 0.3 to 42.7 & ethanol, butyrate, propionate, sludge, synthetic wastewater & 1.2 to 1.3 & $22,80,82,103,104$ \\
\hline
\end{tabular}

Table 2. Summary of the Studies Reporting the Inhibition of Methane Production by CM

\begin{tabular}{|c|c|c|c|c|c|}
\hline conductive material & particle size $/ \mu \mathrm{m}$ & applied concentration/g/L & substrate & methane inhibition $^{a}$ & reference \\
\hline ferrihydrite & $\sim 0.03$ & 2.2 to 4.2 & acetate, ethanol & 1.9 to 4.3 & 24,84 \\
\hline magnesium oxide & $<0.05$ & 0.02 to 10.9 & sludge & 92.6 & 89 \\
\hline silver nanoparticles & $<0.1$ & 0.02 to 10.9 & sludge & 1.4 & 89 \\
\hline carbon black & 0.02 to 0.35 & 4 to 20 & glucose & 51.5 & 105 \\
\hline
\end{tabular}

${ }^{a}$ Number of times that methane production decreases relative to the control.

compared with a control lacking ferrihydrite. ${ }^{26}$ These results highlight the important role of iron biomineralization in the biogeochemical cycling of carbon in diverse anaerobic environments.

3.3. Relationship between CM, ORP, Electrical Conductivity and Methane Production. Despite the high number of research papers reporting the effect of $\mathrm{CM}$ on methane production efficiency (Figure 2), the mechanisms by which CM enhance methanogenic activity are still not known. It was verified that in the presence of CM (specifically multiwalled CNT) the methanogenic activity of pure cultures of methanogens increased significantly, and that it was correlated with the variation of the redox potential (ORP). ${ }^{18}$ Till date, this was the only study monitoring ORP during methanogenesis with CM. In that work, higher concentrations of multiwalled CNT resulted in a growth medium with a more negative ORP, which benefited methanogenesis that ideally occurs at ORP ranging from $-200 \mathrm{mV}$ and $-400 \mathrm{mV}$. Nevertheless, Salvador and co-workers ${ }^{18}$ also observed that in the absence of a reducing agent, the ORP increased (to values reaching approximately $-200 \mathrm{mV}$ ), having the opposite effect verified in the assays performed with the reducing agent. Surprisingly, without reducing agent, the methanogenic activity of Methanobacterium formicicum still increased with increasing concentrations of multiwalled CNT.

The electrical conductivity is another parameter that varies with the presence of $\mathrm{CM}$ in methanogenic systems. The electrical conductivity of anaerobic biomass, biofilms or granules was reported to increase in the presence of CM, namely CNT (27 times), stainless steel (14 times), GAC (3.5 times), ferroferric oxide (2.1 times), carbon cloth (2 times) and biochar (1.5 times). ${ }^{78,79,81,92,98,103}$ This increase has been 


\section{Table 3. Summary of the Studies Using Non-Conductive Materials}

\begin{tabular}{|c|c|c|c|c|}
\hline material & inoculum & substrate & reported effects & reference \\
\hline $\begin{array}{l}\text { polyester cloth (three pieces; } 8 \times \\
\left.20 \times 0.1 \mathrm{~cm}^{3}\right)\end{array}$ & $\begin{array}{l}\text { anaerobic } \\
\text { sludge }\end{array}$ & synthetic complex waste & $\begin{array}{l}\text {-high start-up period } \\
\text {-lower methane content (26\%) } \\
\text {-incomplete degradation of VFAs } \\
\text {-lower total COD removal efficiencies ( } 20 \% \text { to } 31 \%)\end{array}$ & 19 \\
\hline $\begin{array}{l}\text { polyester cloth }(3 \text { pieces; } 8 \times 20 \\
\left.\times 0.1 \mathrm{~cm}^{3}\right)\end{array}$ & $\begin{array}{l}\text { anaerobic } \\
\text { sludge }\end{array}$ & $\begin{array}{l}\text { organic fraction of } \\
\text { municipal solid waste }\end{array}$ & $\begin{array}{l}\text {-no differences in methane production between polyester cloth and } \\
\text { nonamended control reactor }\end{array}$ & 13 \\
\hline $\begin{array}{l}\text { cotton cloth }(20 \times 10 \times 0.05 \mathrm{~cm} \text {, } \\
\left.400 \mathrm{~cm}^{2}\right)\end{array}$ & $\begin{array}{l}\text { anaerobic } \\
\text { sludge }\end{array}$ & $\begin{array}{l}\text { artificial wastewater } \\
\text { (butanol) }\end{array}$ & -high start-up period & 102 \\
\hline silica-coated nanoFe ${ }_{3} \mathrm{O}_{4}(1.1 \mathrm{~g} / \mathrm{L})$ & paddy soil & butyrate & $\begin{array}{l}\text {-similar methane production in silica-coated nanoFe }{ }_{3} \mathrm{O}_{4} \text { to the control } \\
\text { assay without any amendment; }\end{array}$ & 78 \\
\hline plastic threads $(25.7 \mathrm{~g} / \mathrm{L})$ & $\begin{array}{l}\text { anaerobic } \\
\text { sludge }\end{array}$ & artificial wastewater & $\begin{array}{l}-4.5 \text { times less methane production in the reactor with plastic than in } \\
\text { the reactor with stainless steel } \\
\text {-lower COD removal rate } \\
\text {-slightly higher sulfate removal }\end{array}$ & 92 \\
\hline zeolite $(33.3 \mathrm{~g} / \mathrm{L})$ & $\begin{array}{l}\text { anaerobic } \\
\text { sludge }\end{array}$ & acetate & -no effect on methane production. & 98 \\
\hline
\end{tabular}
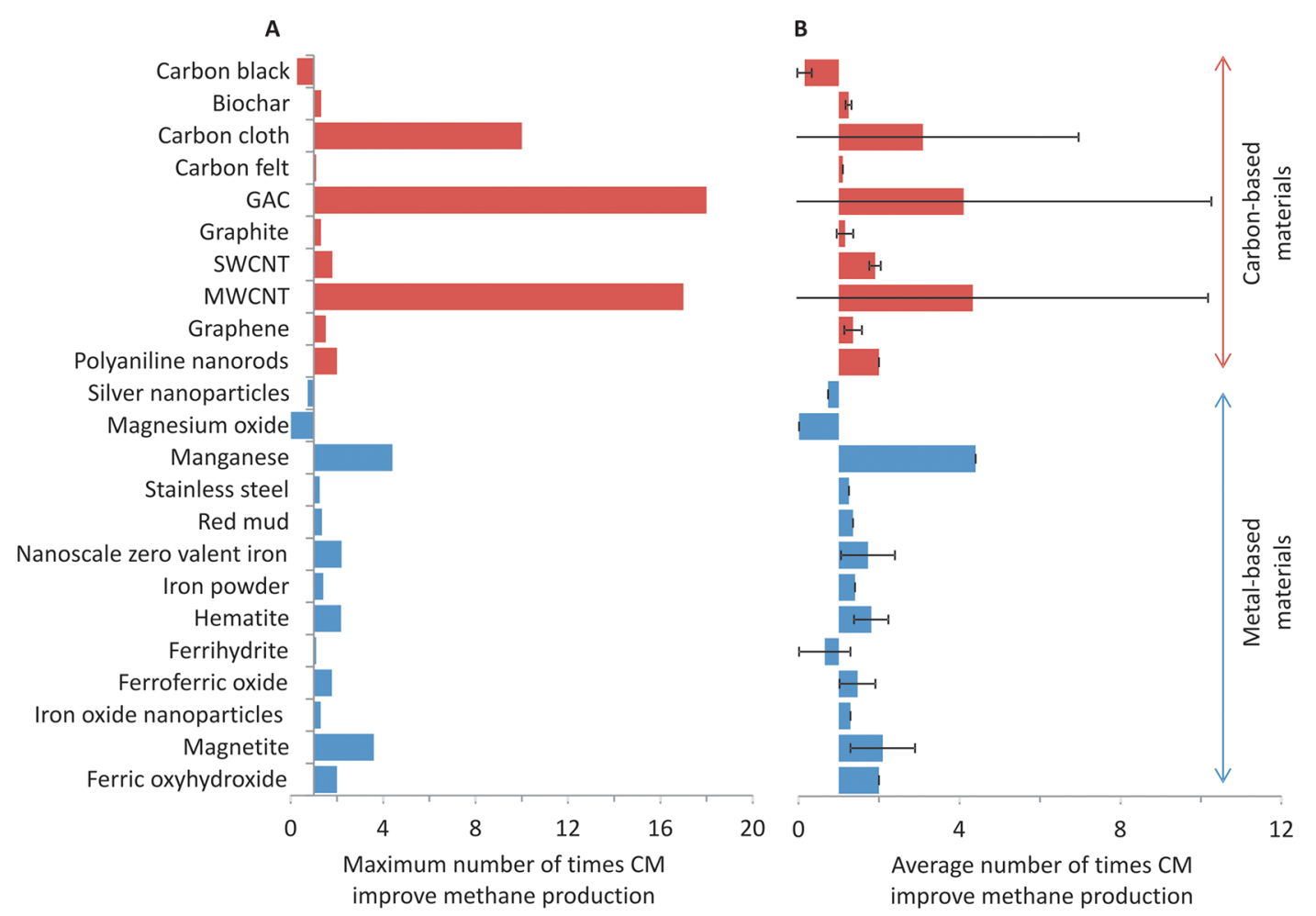

Figure 3. Number of times that methane production increases relatively to control conditions (data from the literature cited in Tables 1,2 and SI Table S1); (a) the best result for each CM; (b) average calculated values for each CM.

justified by a presumable higher expression of electrically conductive pili produced by bacteria which perform DIET, ${ }^{81}$ but also by cations released from these materials, as it was reported for the case of biochar. ${ }^{103}$ However, the electrical conductivity also increased in the presence of non-CM (e.g., plastic threads), ${ }^{92}$ which indicates that electrical conductivity of bulk sludge is affected by materials with high electrical conductivity but also by non-CM. Furthermore, the conductivity seems to vary depending on the metabolism and composition of anaerobic microbial communities, independently of the presence of CM. The conductivity of enrichment cultures previously stimulated with ethanol, and degrading propionate and/or butyrate, was 5 fold higher, for propionate, and 76 fold higher for butyrate, when compared with nonstimulated enrichments (without previous contact with ethanol). ${ }^{100}$ Zhao and co-workers ${ }^{100}$ related the increase in the conductivity to the enrichment of Geobacter species in ethanolstimulated enrichments, which could transfer electrons directly to acetoclastic methanogens. However, although Geobacter's relative abundance increased in enrichments stimulated with ethanol (a common electron donor for several Geobacter species), it represented less than $4 \%$ of the total bacterial community. In the same cultures, Syntrophomonas and Smithella species, well-known as butyrate and propionate degraders, ${ }^{55,120}$ were far more abundant (representing approximately $30 \%$ of the total microbial community).

3.4. The Need of Control Assays. To clarify the role of the electrical conductivity on the enhancement of methane production, control experiments with non-CM are needed. However, to date, only few studies performed control 
experiments with non-CM (Table 3). For example, Li and coworkers $^{92}$ compared the efficiency of two UASB reactors treating sulfate-containing wastewater, one amended with plastic threads and the other with stainless steel. The results showed that more methane was produced $(7.5-24.6 \%)$ in the reactor amended with conductive stainless steel, which was less affected by the sulfate reduction than the reactor with insulated plastic material, although the electric conductivity was higher in both conditions when compared to the initial inoculum. ${ }^{92}$ In another study, the anaerobic digesters supplemented with conductive carbon cloth presented a higher capacity to resist the acidic impacts, and an improved methane production than digesters supplemented with nonconductive cotton cloth. ${ }^{102}$ However, both studies lack control assays without any material. When both controls are performed, that is, controls with nonconductive material and without material, it seems that electrical conductivity is an important parameter. For example, Dang and co-workers ${ }^{13,19}$ showed that in the presence of polyester cloth (nonconductive material), methane production was similar to the control with no material, and lower than when CM are applied. Similarly, the addition of zeolite, as a nonconductive control, did not affect methane production from acetate by comparing to the control without material. ${ }^{98}$ Also, the syntrophic oxidation of butyrate to methane in a paddy soil enrichment was significantly accelerated in the presence of nanoFe $\mathrm{O}_{4}$ (magnetite), but this effect disappeared when magnetite was coated with silica that insulated the mineral from electrical conduction. ${ }^{78}$ Nevertheless, another study attributed the beneficial effect of carbon felt, during the $\mathrm{AD}$ of molasses, to the increase of biomass retention rather than to the conductive characteristics of the material. ${ }^{121}$ This fact indicates that the support for biomass attachment provided by the materials could also be an important parameter in the enhancement of methane production. ${ }^{121}$ Indeed, Salvador and co-workers $^{18}$ showed that the positive effect provided by multiwalled CNT on the methane production by M. formicicum is dismissed when the multiwalled CNT are removed from the culture media, once again pointing out for the importance of the physical presence of the carbon material.

3.5. The Physical and Chemical Characteristics of CM and Microbial Colonization. Independently of the application, the physical and chemical characteristics of $\mathrm{CM}$ are of utmost importance. Assays with similar CM with slightly different modifications may return significantly different results (Figure 3, Table 1). All materials are unique and even when they present similar general characteristics, their physical and chemical behavior and therefore the way they influence the biological reactions, can be potentially different. Some of the physicochemical characteristics of $\mathrm{CM}$ used in $\mathrm{AD}$, namely the BET surface area, the electrical conductivity and the $\mathrm{pH}$ of point zero charge $\left(\mathrm{pH}_{\mathrm{pzc}}\right)$, are summarized in SI Table S3. The basicity and acidity of the materials are correlated with the chemical groups present at their surface, that is, materials with high content of acidic groups at the surface such as phenols and carbonyl/quinone groups are more acidic and materials with low oxygen containing groups, present basic character. The $\mathrm{pHpzc}$ gives the net charge of the material, as a function of the solution $\mathrm{pH}$ : the surface of the materials becomes positively charged at $\mathrm{pH}<\mathrm{pHpzc}$ and negatively charged at $\mathrm{pH}>$ pHpzc. In the case of magnetic nanomaterials, smaller particle sizes increase their performance, due to the increase of atoms on the surface and near the surface of the material, which are prone to adsorb and react with other atoms or molecules so as to attain surface stabilization. However, smaller particles sizes increase the surface energy, decreasing stability and leading to agglomeration and precipitation. ${ }^{122}$

It is known that bacterial activity may increase in the presence of solids/physical supports, especially in very dilute nutrient solutions. ${ }^{123}$ This may be related with the concentration of nutrients in the surface of the solid by adsorption, ${ }^{123,124}$ and by the retardation of the diffusion of exoenzymes and hydrolyzates away from the cell, ${ }^{123}$ thereby promoting the assimilation of nutrients which must be first hydrolyzed. However, the fact that higher substrate and nutrient concentrations can be found at the solid surface does not explain per se better microbial activities. ${ }^{125}$ In addition, the effect of the solids toward microbial activities depend on the nature of the microorganisms, the type and concentration of the substrates, and the nature of the solid surfaces. ${ }^{125}$

Surface roughness and surface free energy of solid materials have a potential role on microbial activity of adhered cells. ${ }^{126}$ In general, microorganisms tend to adhere in larger extent to roughest surfaces which provide a higher specific surface area for cell adhesion. The protrusions from the rougher surfaces also increase the contact frequency between cells and surfaces. ${ }^{127}$ Surface free energy has a significant role in the adsorption, adhesion, and wetting, ${ }^{128}$ affecting the phenomena occurring at the solid-liquid interface. Habouzit and coworkers $^{129}$ found that low surface free energy materials, such as polypropylene, stainless steel, and polyethylene, facilitate the first stage of colonization of the support by the anaerobic digester biomass. The low surface free energy materials were found to be more easily colonized by methanogens. ${ }^{129}$

Regarding the application of CM in methane driven systems, major improvements in methane production rates were obtained with carbon based-CM, specifically with GAC, multiwalled CNT and carbon cloth (Figure 3B). Indeed, best results with $\mathrm{CM}$ were obtained with carbon-based materials that present higher surface areas, although lower electrical conductivities, when compared with metal-based CM (Figure 3 , SI Table S3). However, there is no correlation between the electrical conductivity and the enhancement in methane production $\left(R^{2}<0.1\right.$, data not shown). Nevertheless, it is important to note that the available values for electrical conductivity are scarce which limits this analysis. On the other hand, the initial rate and the long-term extent of synthetic iron(III) oxides reduction were linearly correlated with the oxide surface area. ${ }^{130}$ However, other factors such as crystal structure, morphology, free energy, and particle aggregation also had an important influence on microbial metal oxide reduction rates. ${ }^{130}$

In addition, carbon based-CM had a similar role of humic substances and soluble quinones during the biological degradation of organic pollutants. ${ }^{131}$ Small amounts of activated carbon, carbon xerogels, CNT, carbon fibers, biochar and graphene, accelerated the electron transfer from an electron donor to organic pollutants (as the final acceptors), improving significantly the reduction rates. Some examples include the reduction of azo dyes, ${ }^{30,131-136}$ nitrocompounds, ${ }^{137-141}$ herbicides $^{142}$ and pharmaceutical compounds. ${ }^{143,144}$ The key factor is that these materials act as electron shuttles by receiving and donating electrons either biotically or abiotically. The electron shuttling via carbon materials was initially ascribed to the existing quinone moieties but recent studies showed that the shuttling effect is uncoupled from the existence of quinones in the surface of the materials. 
Pereira and co-workers ${ }^{131}$ showed that higher rates of azo dye reduction were obtained with activated carbon containing less oxygen-containing groups, and that it was due to the high content of electron rich sites on their basal planes (electrons $\pi$ ) and by a low concentration of electron withdrawing groups.

\section{EFFECT OF CONDUCTIVE MATERIALS ON COMPLEX MICROBIAL COMMUNITIES}

It is unquestionable that generally $\mathrm{CM}$ enhance the efficiency of methane production, but the reasons why it happens remain unclear. To better understand this phenomenon, the microbial communities are often studied with the objective to (1) identify the most important microbial players, (2) investigate the interspecies microbial interactions; and (3) get insights into the interspecies electron transfer mechanisms.

In most studies performed with $\mathrm{CM}$, the microbial community analysis is based on the taxonomic composition obtained by sequencing the $16 \mathrm{~S}$ rRNA genes. When using next generation sequencing technologies such as Illumina sequencing or 454-pyrosequecing, also the relative abundance of the microorganisms identified can be obtained. However, changes in community composition do not directly inform changes in the mechanisms of interspecies electron transfer. Nevertheless, in a significant number of studies the improvement of microbial activities in the presence of $\mathrm{CM}$ is usually justified by the shift of IET to DIET. This conclusion appears as a consequence of the detection of Geobacter species, which are known to exchange electrons directly with acetoclastic methanogens. ${ }^{6,8}$ In some studies, the enrichment of Geobacter was verified closely attached to $\mathrm{CM},{ }^{1,15,23,80,145-147}$ suggesting that the electron transfer mechanism in the consortia could change to, or include DIET. However, in the majority of the studies Geobacter species are present in low percentages $^{21,99-101}$ or even absent. ${ }^{14,17,19,81,94}$ Notwithstanding these results, the conclusion that methane production is enhanced by shifting the IET to DIET is often maintained. Even when electroactive bacteria are not detected, other microorganisms have been suggested to participate in DIET. For example, it was suggested that Syntrophomonas sp. could exchange electrons directly with Methanospirillum hungatei, based on the fact that they were the most abundant microorganisms in a carbon cloth stimulated consortia. ${ }^{81}$ However, this conclusion had no experimental support, and fundamental studies performed with $M$. hungatei revealed its inability to receive electrons directly from Geobacter. ${ }^{6}$

The focus on Geobacter species and the assumption that DIET prevails in methanogenic environments amended with $\mathrm{CM}$, disregards the importance of other potential microbial players. In fact, microorganisms closely related to typical hydrogen forming and syntrophic bacteria were enriched in assays performed with CM where methane production was enhanced. For example, Syntrophomonas, Desulfotomaculum, and Smithella were enriched with GAC; ${ }^{19,82,100}$ Syntrophomonas with magnetite and hematite; ${ }^{16,24,78}$ Clostridium ( $~ 50 \%$ of the community) with polymerized conductive polyaniline nanorods ${ }^{94}$ and with conductive carbon felt (from $28 \%$ to $41 \%$ of the community); ${ }^{101}$ Syntrophobacter with magnetite; Sporanaerobacter (representing approximately 30\% of the bacterial community) with carbon cloth, ${ }^{13}$ and Syntrophomonas also with carbon cloth (SI Table S2). ${ }^{81}$

Not all microorganisms are able to perform DIET, and the research available suggests that this may be the case of the vast majority of the anaerobic microorganisms. Experimental evidence collected until date, point out for the inability of some Syntrophomonas ${ }^{18}$ and Pelobacter species ${ }^{11}$ to participate in DIET.

DIET does not always explain the enhancement of methane production. For example, magnetite was found to accelerate the oxidation of propionate by acting as an electron acceptor, rather than promoting DIET. ${ }^{27}$ Similarly, Kato and coworkers $^{24}$ reported ferrihydrite reduction to ferrous ions by Geobacter in methanogenic cultures.

It was also demonstrated that increasing concentrations of multiwalled CNT, a carbon based conductive material, promoted increasing methanogenic activities of four different species of methanogens growing in pure cultures. ${ }^{18}$ Methane production rates increased up to 17 times in pure cultures of Methanobacterium formicicum. ${ }^{18}$ This finding proved that the effect of CM toward microbial communities goes beyond the interactions between different species of microorganisms. The fact that these materials affect the activity of methanogens in pure cultures, should be considered when interpreting the effect of similar materials toward the same microorganisms when growing in complex microbial communities.

As it was mentioned before, CM inhibited the methanogenic communities in a minor number of cases (Table 2). High concentrations of $\mathrm{Ag}$ and $\mathrm{MgO}$ nanoparticles (i.e., $500 \mathrm{mgAg}$ / gTSS and $500 \mathrm{mgMgO} / \mathrm{gTSS}$ ), reduced the abundance of bacterial and archaeal populations in $84 \%$ and $32 \%$ relatively to the control, respectively. ${ }^{89}$ In addition, $\alpha$-Proteobacteria, $\beta$ Proteobacteria, Bacteroidetes, and Methanosaeta were less active, and a significant decrease on enzymatic activities (e.g., proteases, acetate kinases and coenzyme F420) could be detected in the reactors exposed to $\mathrm{Ag}$ and $\mathrm{MgO}$ nanoparticles. ${ }^{89}$ The supplementation of ferrihydrite also lead to microbial community changes. ${ }^{24,84}$ For example, while Methanosarcina spp. were abundantly detected both in ferrihydrite $^{24,84}$ and magnetite ${ }^{24}$ cultures, Methanobacterium was only detected in the control and in ferrihydrite supplemented cultures, being apparently inhibited by magnetite. $^{24}$

\section{CONCLUSIONS AND FUTURE PERSPECTIVES}

Generally, CM improve the conversion of organic waste to methane by anaerobic microbial communities. Nevertheless, some CM (i.e., ferrihydrite, carbon black, $\mathrm{Ag}$, and $\mathrm{Mg}$ nanoparticles) were reported to inhibit methane production. Carbon-based CM stimulated methanogenic communities in a larger extent than metal-based CM. However, it is hard to compare the effect of different CM since they present different physical and chemical characteristics (e.g., surface area, shape, pore size and volume, electrical conductivity, $\mathrm{pH}_{\mathrm{pzc}}$ ) and were applied in different systems with distinct substrates, inocula, and operational conditions.

The mechanisms behind the effect of $\mathrm{CM}$ are not well understood but it seems that more than one factor is responsible for the changes toward microbial activities. The electrical conductivity of biofilms, the redox potential of the growth medium, the specific surface area and the roughness of the materials seem to be important factors. Control assays with nonconductive materials are important for understanding the effect of CM, but such controls were rarely performed.

More studies with pure cultures and cocultures need to be conducted, as well as control assays. For example, studies with defined cocultures and different CM with distinct electrical conductivities and surface areas should help in the clarification 
of the role of these characteristics in the enhancement of methane production. Additional molecular biology methodologies should also be employed in order to get more functional data in addition to taxonomic information. For instance, analyzing the taxonomy based in 16S rRNA collected from RNA extracts in alternative to DNA extracts, measuring enzymes activities or following protein expression, would help to draw more reliable conclusions and to link microbial identity to activity. Metagenomics, metatranscriptomics and metaproteomics may be used to unravel microbial interactions and activities in uncultivable microbial communities. In addition, more studies should be performed in order to understand which trophic groups are directly affected by $\mathrm{CM}$, if the methanogens, the bacteria or both.

A deeper microbial community analysis however, does not discard the need to explore more extensively the system. Measuring as much parameters as possible (e.g., redox potential, electric conductivity, methane, hydrogen, formate, among other parameters) and performing all necessary controls.

Another important issue that should be addressed is the economic and environmental impact of the continuous addition of $\mathrm{CM}$ to bioreactors. In some cases, the price of $\mathrm{CM}$ is very high, and the continuous addition is not economically feasible. The use of magnetic CM may be an interesting alternative since they can be easily recovered and reutilized due to their magnetic properties. These nanocomposites of carbon and magnetic nanomaterials present a high surface area, proper pore size and excellent catalytic properties. Also, the growth of carbon nanofibers in the surface of ceramic monoliths, and the immobilization of CM (eventually chemically and/or physically modified) in silicon foam may result in a superior macrostructured catalyst with tailored properties for specific applications.

Despite the yet limited knowledge on this topic, the application of CM appears as a good strategy to improve the methane production rates. Their application turns anaerobic systems more resilient to upsets caused by high organic loading rates or toxic compounds, and increase the competitiveness of $\mathrm{AD}$ in waste treatment and bioenergy production.

\section{ASSOCIATED CONTENT}

\section{S Supporting Information}

The Supporting Information is available free of charge on the ACS Publications website at DOI: 10.1021/acs.est.8b01913.

Three supporting tables that summarize the key studies regarding the enhancement of methane production by CM. Table S1 presents the conductive material, the type of reactor, the inoculum and the substrate used, as well as the reported effect on methane production. Table S2 presents the methods used for microbial community analysis and the reported microbial compositions. Table S3 summarize some of the physicochemical characteristics of $\mathrm{CM}$ used in $\mathrm{AD}$ (PDF)

\section{AUTHOR INFORMATION}

\section{Corresponding Author}

*Phone:(+351) 253601986; e-mail: gilberto.martins@deb. uminho.pt.

ORCID $\odot$

Gilberto Martins: 0000-0001-7187-0538

\section{Author Contributions}

The manuscript was written through contributions of all authors. All authors have given approval to the final version of the manuscript.

\section{Notes}

The authors declare no competing financial interest.

\section{ACKNOWLEDGMENTS}

This study was supported by the European Research Council under the European Union's Seventh Framework Programme (FP/2007-2013)/ERC Grant Agreement no. 323009 and by the Portuguese Foundation for Science and Technology (FCT) under the scope of the strategic funding of UID/ BIO/04469/2013 unit, COMPETE 2020 (POCI-01-0145FEDER-006684) and project PAC MultiBiorefinery SAICTPAC/0040/2015 (POCI-01-0145-FEDER-016403), and BioTecNorte operation (NORTE-01-0145-FEDER-000004) funded by the European Regional Development Fund under the scope of Norte2020 - Programa Operacional Regional do Norte. We acknowledge the fellowships awarded to Gilberto Martins (SFRH/BPD/80528/2011) and Luciana Pereira (SFRH/BPD/110235/2015) under the scope of the program $\mathrm{POPH} / \mathrm{ESF}$.

\section{REFERENCES}

(1) Baek, G.; Kim, J.; Cho, K.; Bae, H.; Lee, C. The Biostimulation of Anaerobic Digestion with (Semi)Conductive Ferric Oxides: Their Potential for Enhanced Biomethanation. Appl. Microbiol. Biotechnol. 2015, 99 (23), 10355-10366.

(2) McInerney, M. J.; Struchtemeyer, C. G.; Sieber, J.; Mouttaki, H.; Stams, A. J. M.; Schink, B.; Rohlin, L.; Gunsalus, R. P. Physiology, Ecology, Phylogeny, and Genomics of Microorganisms Capable of Syntrophic Metabolism. Ann. N. Y. Acad. Sci. 2008, 1125, 58-72.

(3) Stams, A. J. M.; Plugge, C. M. Electron Transfer in Syntrophic Communities of Anaerobic Bacteria and Archaea. Nat. Rev. Microbiol. 2009, 7 (8), 568-577.

(4) Stams, A. J. M. Metabolic Interactions between Anaerobic Bacteria in Methanogenic Environments. Antonie van Leeuwenhoek 1994, 66 (1), 271-294.

(5) Nagarajan, H.; Embree, M.; Rotaru, A. E.; Shrestha, P. M.; Feist, A. M.; Palsson, B. Ø.; Lovley, D. R.; Zengler, K. Characterization and Modelling of Interspecies Electron Transfer Mechanisms and Microbial Community Dynamics of a Syntrophic Association. Nat. Commun. 2013, 4, 2809.

(6) Rotaru, A. E.; Shrestha, P. M.; Liu, F.; Shrestha, M.; Shrestha, D.; Embree, M.; Zengler, K.; Wardman, C.; Nevin, K. P.; Lovley, D. R. A New Model for Electron Flow during Anaerobic Digestion: Direct Interspecies Electron Transfer to Methanosaeta for the Reduction of Carbon Dioxide to Methane. Energy Environ. Sci. 2014, 7 (1), 408415.

(7) Lovley, D. R. Happy Together: Microbial Communities That Hook up to Swap Electrons. ISME J. 2017, 11, 327-336.

(8) Rotaru, A. E.; Shrestha, P. M.; Liu, F.; Markovaite, B.; Chen, S.; Nevin, K. P.; Lovley, D. R. Direct Interspecies Electron Transfer between Geobacter metallireducens and Methanosarcina barkeri. Appl. Environ. Microbiol. 2014, 80 (15), 4599-4605.

(9) Sieber, J. R.; Le, H. M.; Mcinerney, M. J. The Importance of Hydrogen and Formate Transfer for Syntrophic Fatty, Aromatic and Alicyclic Metabolism. Environ. Microbiol. 2014, 16 (1), 177-188.

(10) Thauer, R. K.; Kaster, A. K.; Seedorf, H.; Buckel, W.; Hedderich, R. Methanogenic Archaea: Ecologically Relevant Differences in Energy Conservation. Nat. Rev. Microbiol. 2008, 6 (8), 579591.

(11) Rotaru, A. E.; Shrestha, P. M.; Liu, F.; Ueki, T.; Nevin, K.; Summers, Z. M.; Lovley, D. R. Interspecies Electron Transfer via Hydrogen and Formate Rather than Direct Electrical Connections in 
Cocultures of Pelobacter carbinolicus and Geobacter sulfurreducens. Appl. Environ. Microbiol. 2012, 78 (21), 7645-7651.

(12) Haveman, S. A.; Holmes, D. E.; Ding, Y. H. R.; Ward, J. E.; DiDonato, R. J.; Lovley, D. R. C-Type Cytochromes in Pelobacter carbinolicus. Appl. Environ. Microbiol. 2006, 72 (11), 6980-6985.

(13) Dang, Y.; Holmes, D. E.; Zhao, Z.; Woodard, T. L.; Zhang, Y.; Sun, D.; Wang, L. Y.; Nevin, K. P.; Lovley, D. R. Enhancing Anaerobic Digestion of Complex Organic Waste with Carbon-Based Conductive Materials. Bioresour. Technol. 2016, 220, 516-522.

(14) Yin, Q.; Miao, J.; Li, B.; Wu, G. Enhancing Electron Transfer by Ferroferric Oxide during the Anaerobic Treatment of Synthetic Wastewater with Mixed Organic Carbon. Int. Biodeterior. Biodegrad. 2016, 119, 4-10.

(15) Lee, J. Y.; Lee, S. H.; Park, H. D. Enrichment of Specific Electro-Active Microorganisms and Enhancement of Methane Production by Adding Granular Activated Carbon in Anaerobic Reactors. Bioresour. Technol. 2016, 205, 205-212.

(16) Zhang, J.; Lu, Y. Conductive Fe3O4 Nanoparticles Accelerate Syntrophic Methane Production from Butyrate Oxidation in Two Different Lake Sediments. Front. Microbiol. 2016, 7, 1-9.

(17) Jing, Y.; Wan, J.; Angelidaki, I.; Zhang, S.; Luo, G. ITRAQ Quantitative Proteomic Analysis Reveals the Pathways for Methanation of Propionate Facilitated by Magnetite. Water Res. 2017, 108, 212-221.

(18) Salvador, A. F.; Martins, G.; Melle-Franco, M.; Serpa, R.; Stams, A. J. M.; Cavaleiro, A. J.; Pereira, M. A.; Alves, M. M. Carbon Nanotubes Accelerate Methane Production in Pure Cultures of Methanogens and in a Syntrophic Coculture. Environ. Microbiol. 2017, 19 (7), 2727-2739.

(19) Dang, Y.; Sun, D.; Woodard, T. L.; Wang, L. Y.; Nevin, K. P.; Holmes, D. E. Stimulation of the Anaerobic Digestion of the Dry Organic Fraction of Municipal Solid Waste (OFMSW) with CarbonBased Conductive Materials. Bioresour. Technol. 2017, 238, 30-38.

(20) Liu, F.; Rotaru, A. E.; Shrestha, P. M.; Malvankar, N. S.; Nevin, K. P.; Lovley, D. R. Promoting Direct Interspecies Electron Transfer with Activated Carbon. Energy Environ. Sci. 2012, 5 (10), 8982.

(21) Xu, S.; He, C.; Luo, L.; Lü, F.; He, P.; Cui, L. Comparing Activated Carbon of Different Particle Sizes on Enhancing Methane Generation in Upflow Anaerobic Digester. Bioresour. Technol. 2015, 196, 606-612.

(22) Chen, S.; Rotaru, A. E.; Shrestha, P. M.; Malvankar, N. S.; Liu, F.; Fan, W.; Nevin, K. P.; Lovley, D. R. Promoting Interspecies Electron Transfer with Biochar. Sci. Rep. 2015, 4, 5019.

(23) Cruz Viggi, C.; Rossetti, S.; Fazi, S.; Paiano, P.; Majone, M.; Aulenta, F. Magnetite Particles Triggering a Faster and More Robust Syntrophic Pathway of Methanogenic Propionate Degradation. Environ. Sci. Technol. 2014, 48 (13), 7536-7543.

(24) Kato, S.; Hashimoto, K.; Watanabe, K. Methanogenesis Facilitated by Electric Syntrophy via (Semi)Conductive Iron-Oxide Minerals. Environ. Microbiol. 2012, 14 (7), 1646-1654.

(25) Zhuang, L.; Tang, J.; Wang, Y.; Hu, M.; Zhou, S. Conductive Iron Oxide Minerals Accelerate Syntrophic Cooperation in Methanogenic Benzoate Degradation. J. Hazard. Mater. 2015, 293 (808), $37-45$.

(26) Tang, J.; Zhuang, L.; Ma, J.; Tang, Z.; Yu, Z.; Zhou, S. Secondary Mineralization of Ferrihydrite Affects Microbial Methanogenesis in Geobacter-Methanosarcina Cocultures. Appl. Environ. Microbiol. 2016, 82 (19), 5869-5877.

(27) Yang, Z.; Guo, R.; Shi, X.; Wang, C.; Wang, L.; Dai, M. Magnetite Nanoparticles Enable a Rapid Conversion of Volatile Fatty Acids to Methane. RSC Adv. 2016, 6 (31), 25662-25668.

(28) Figueiredo, J. L.; Pereira, M. F. R.; Freitas, M. M. . A.; Órfão, J. J. M. Modification of the Surface Chemistry of Activated Carbons. Carbon 1999, 37 (9), 1379-1389.

(29) Van der Zee, F. P.; Cervantes, F. J. Impact and Application of Electron Shuttles on the Redox (Bio)Transformation of Contaminants: A Review. Biotechnol. Adv. 2009, 27 (3), 256-277.
(30) Pereira, R. A.; Pereira, M. F. R.; Alves, M. M.; Pereira, L. Carbon Based Materials as Novel Redox Mediators for Dye Wastewater Biodegradation. Appl. Catal., B 2014, 144, 713-720.

(31) Barua, S.; Dhar, B. R. Advances towards Understanding and Engineering Direct Interspecies Electron Transfer in Anaerobic Digestion. Bioresour. Technol. 2017, 244, 698-707.

(32) Park, J. H.; Kang, H. J.; Park, K. H.; Park, H. D. Direct Interspecies Electron Transfer via Conductive Materials: A Perspective for Anaerobic Digestion Applications. Bioresour. Technol. 2018, 254 (February), 300-311.

(33) Baek, G.; Kim, J.; Kim, J.; Lee, C. Role and Potential of Direct Interspecies Electron Transfer in Anaerobic Digestion. Energies 2018, 11 (1).107

(34) Ahn, H. K.; Smith, M. C.; Kondrad, S. L.; White, J. W. Evaluation of Biogas Production Potential by Dry Anaerobic Digestion of Switchgrass-Animal Manure Mixtures. Appl. Biochem. Biotechnol. 2010, 160 (4), 965-975.

(35) Meslé, M.; Dromart, G.; Oger, P. Microbial Methanogenesis in Subsurface Oil and Coal. Res. Microbiol. 2013, 164 (9), 959-972.

(36) Senghor, A.; Dioh, R. M. N.; Müller, C.; Youm, I. Cereal Crops for Biogas Production: A Review of Possible Impact of Elevated; Renewable Sustainable Energy Rev. 2016; December, 711-7.

(37) Lier, J. B. Van.; Mahmoud, N.; Zeeman, G. Anaerobic Wastewater Treatment. In Biological Wastewater Treatment: Principles, Modelling and Design; Henze, M., van Loosdrecht, M., Ekama, G., Brdjanovic, D., Eds.; IWA: London, 2008; pp 401-442.

(38) Park, C.; Lee, C.; Kim, S.; Chen, Y.; Chase, H. A. Upgrading of Anaerobic Digestion by Incorporating Two Different Hydrolysis Processes. J. Biosci. Bioeng. 2005, 100 (2), 164-167.

(39) Ziganshin, A. M.; Liebetrau, J.; Pröter, J.; Kleinsteuber, S. Microbial Community Structure and Dynamics during Anaerobic Digestion of Various Agricultural Waste Materials. Appl. Microbiol. Biotechnol. 2013, 97 (11), 5161-5174.

(40) Sträuber, H.; Lucas, R.; Kleinsteuber, S. Metabolic and Microbial Community Dynamics during the Anaerobic Digestion of Maize Silage in a Two-Phase Process. Appl. Microbiol. Biotechnol. 2016, 100 (1), 479-491.

(41) Stams, A. J. M.; de Bok, F. A. M.; Plugge, C. M.; van Eekert, M. H. A.; Dolfing, J.; Schraa, G. Exocellular Electron Transfer in Anaerobic Microbial Communities. Environ. Microbiol. 2006, 8 (3), $371-382$.

(42) Lovley, D. R. Syntrophy Goes Electric: Direct Interspecies Electron Transfer. Annu. Rev. Microbiol. 2017, 71, 643-664.

(43) Kouzuma, A.; Kato, S.; Watanabe, K. Microbial Interspecies Interactions: Recent Findings in Syntrophic Consortia. Front. Microbiol. 2015, 6, 1-8.

(44) Morris, B. E. L.; Henneberger, R.; Huber, H.; Moissl-Eichinger, C. Microbial Syntrophy: Interaction for the Common Good. FEMS Microbiol. Rev. 2013, 37 (3), 384-406.

(45) Schink, B.; Montag, D.; Keller, A.; Müller, N. Hydrogen or Formate - Alternative Key Players in Methanogenic Degradation. Environ. Microbiol. Rep. 2017.9189

(46) Schink, B.; Stams, A. J. M. Syntrophism Among Prokaryotes. In The Prokaryotes: Prokaryotic Communities and Ecophysiology; Rosenberg, E., DeLong, E. F., Lory, S., Stackebrandt, E., Thompson, F., Eds.; Springer Berlin Heidelberg: Berlin, Heidelberg, 2013; pp 471-493.

(47) Sieber, J. R.; McInerney, M. J.; Gunsalus, R. P. Genomic Insights into Syntrophy: The Paradigm for Anaerobic Metabolic Cooperation. Annu. Rev. Microbiol. 2012, 66, 429-452.

(48) Garcia, J.-L.; Patel, B. K. C.; Ollivier, B. Taxonomic, Phylogenetic, and Ecological Diversity of Methanogenic Archaea. Anaerobe 2000, 6 (4), 205-226.

(49) Schink, B. Energetics of Syntrophic Cooperation in Methanogenic Degradation. Microbiol. Mol. Biol. Rev. 1997, 61 (2), $262-280$.

(50) Zindel, U.; Freudenberg, W.; Rieth, M.; Andreesen, J. R.; Schnell, J.; Widdel, F. Eubacterium acidaminophilum sp. nov., a 
Versatile Amino Acid-Degrading Anaerobe Producing or Utilizing H2 or Formate. Arch. Microbiol. 1988, 150 (3), 254-266.

(51) De Bok, F. A. M.; Plugge, C. M.; Stams, A. J. M. Interspecies Electron Transfer in Methanogenic Propionate Degrading Consortia. Water Res. 2004, 38 (6), 1368-1375.

(52) Sousa, D. Z.; Smidt, H.; Madalena Alves, M.; Stams, A. J. M. Syntrophomonas zehnderi sp. nov., an Anaerobe That Degrades LongChain Fatty Acids in Co-Culture with Methanobacterium Formicicum. Int. J. Syst. Evol. Microbiol. 2007, 57 (3), 609-615.

(53) Boone, D. R.; Johnson, R. L.; Liu, Y. Diffusion of the Interspecies Electron Carriers $\mathrm{H}_{2}$ and Formate in Methanogenic Ecosystems and Its Implications in the Measurement of $\mathrm{K}_{\mathrm{m}}$ for $\mathrm{H}_{2}$ or Formate Uptake. Appl. Environ. Microbiol. 1989, 55 (7), 1735-1741.

(54) Shrestha, P. M.; Rotaru, A. E. Plugging in or Going Wireless: Strategies for Interspecies Electron Transfer. Front. Microbiol. 2014, 5, $1-8$.

(55) McInerney, M. J.; Bryant, M. P.; Hespell, R. B.; Costerton, J. W. Syntrophomonas wolfei gen. nov. sp. nov., an Anaerobic, Syntrophic, Fatty Acid-Oxidizing Bacterium. Appl. Environ. Microbiol. 1981, 41 (4), 1029-1039.

(56) Harmsen, H. J. M.; Kuijk, B. L. M. Van; Plugge, C. M.; Akkermans, A. D. L.; Vos, W. M. De; Stams, A. J. M. Syntrophobacter furnaroxidans sp. nov., a Syntrophic Propionate-Degrading Sulfate Reducing Bacterium. Int. J. Syst. Bacteriol. 1998, 48, 1383-1388.

(57) Schink, B. Fermentation of 2,3-Butanediol by Pelobacter carbinolicus sp. nov. and Pelobacter propionicus sp. nov., and Evidence for Propionate Formation from C2 Compounds. Arch. Microbiol. 1984, 137 (1), 33-41.

(58) Cord-Ruwisch, R.; Lovley, D. R.; Schink, B. Growth of Geobacter sulfurreducens with Acetate in Syntrophic Cooperation with Hydrogen-Oxidizing Anaerobic Partners. Appl. Environ. Microbiol. 1998, 64 (6), 2232-2236.

(59) Cervantes, F. J.; De Bok, F. A. M.; Duong-Dac, T.; Stams, A. J. M.; Lettinga, G.; Field, J. A. Reduction of Humic Substances by Halorespiring, Sulphate-Reducing and Methanogenic Microorganisms. Environ. Microbiol. 2002, 4 (1), 51-57.

(60) Ratasuk, N.; Nanny, M. A. Characterization and Quantification of Reversible Redox Sites in Humic Substances. Environ. Sci. Technol. 2007, 41 (22), 7844-7850.

(61) Hernández-Montoya, V.; Alvarez, L. H.; Montes-Morán, M. A.; Cervantes, F. J. Reduction of Quinone and Non-Quinone Redox Functional Groups in Different Humic Acid Samples by Geobacter sulfurreducens. Geoderma 2012, 183-184, 25-31.

(62) Piepenbrock, A.; Schröder, C.; Kappler, A. Electron Transfer from Humic Substances to Biogenic and Abiogenic Fe(III) Oxyhydroxide Minerals. Environ. Sci. Technol. 2014, 48 (3), 1656-1664.

(63) Holmes, D. E.; Smith, J. A. Biologically Produced Methane as a Renewable Energy Source. Adv. Appl. Microbiol. 2016, 97, 1-61.

(64) Lovley, D. R.; Fraga, J. L.; Coates, J. D.; Blunt-Harris, E. L. Humics as an Electron Donor for Anaerobic Respiration. Environ. Microbiol. 1999, 1 (1), 89-98.

(65) dos Santos, A. B.; Cervantes, F. J.; van Lier, J. B. Azo Dye Reduction by Thermophilic Anaerobic Granular Sludge, and the Impact of the Redox Mediator Anthraquinone-2,6-Disulfonate (AQDS) on the Reductive Biochemical Transformation. Appl. Microbiol. Biotechnol. 2004, 64 (1), 62-69.

(66) Coates, J. D.; Ellis, D. J.; Blunt-Harris, E. L.; Gaw, C. V.; Roden, E. E.; Lovley, D. R. Recovery of Humic-Reducing Bacteria from a Diversity of Environments. Appl. Environ. Microbiol. 1998, 64 (4), 1504-1509.

(67) Coates, J. D.; Bhupathiraju, V. K.; Achenbach, L. A.; McInerney, M. J.; Lovley, D. R. Geobacter hydrogenophilus, Geobacter chapellei and Geobacter grbiciae, Three New, Strictly Anaerobic, Dissimilatory Fe(III)-Reducers. Int. J. Syst. Evol. Microbiol. 2001, 51 (2), 581-588.

(68) Lovley, D. R.; Coates, J. D.; Blunt-Harris, E. L.; Phillips, E. J. P.; Woodward, J. C. Humic Substances as Electron Acceptors for Microbial Respiration. Nature 1996, 382, 445.
(69) Lovley, D. R.; Fraga, J. L.; Blunt-Harris, E. L.; Hayes, L. A.; Phillips, E. J. P.; Coates, J. D. Humic Substances as a Mediator for Microbially Catalyzed Metal Reduction. Acta Hydrochim. Hydrobiol. 1998, 26 (3), 152-157.

(70) Lovley, D. R.; Kashefi, K.; Vargas, M.; Tor, J. M.; Blunt-Harris, E. L. Reduction of Humic Substances and Fe(III) by Hyperthermophilic Microorganisms. Chem. Geol. 2000, 169 (3-4), 289298.

(71) Summers, Z. M.; Fogarty, H. E.; Leang, C.; Franks, A. E.; Malvankar, N. S.; Lovley, D. R. Direct Exchange of Electrons within Aggregates of an Evolved Syntrophic Coculture of Anaerobic Bacteria. Science 2010, 330, 1413-1415.

(72) Storck, T.; Virdis, B.; Batstone, D. J. Modelling Extracellular Limitations for Mediated versus Direct Interspecies Electron Transfer. ISME J. 2016, 10 (3), 621-631.

(73) Shrestha, P. M.; Rotaru, A. E.; Summers, Z. M.; Shrestha, M.; Liu, F.; Lovely, D. R. Transcriptomic and genetic analysis of direct interspecies electron transfer. Appl. Environ. Microbiol. 2013, 79, 2397-2404.

(74) Chen, S.; Rotaru, A. E.; Liu, F.; Philips, J.; Woodard, T. L.; Nevin, K. P.; Lovley, D. R. Carbon Cloth Stimulates Direct Interspecies Electron Transfer in Syntrophic Co-Cultures. Bioresour. Technol. 2014, 173, 82-86.

(75) Liu, F.; Rotaru, A. E.; Shrestha, P. M.; Malvankar, N. S.; Nevin, K. P.; Lovley, D. R. Magnetite Compensates for the Lack of a PilinAssociated c-Type Cytochrome in Extracellular Electron Exchange. Environ. Microbiol. 2015, 17 (3), 648-655.

(76) Romero-Güiza, M. S.; Vila, J.; Mata-Alvarez, J.; Chimenos, J. M.; Astals, S. The Role of Additives on Anaerobic Digestion: A Review. Renewable Sustainable Energy Rev. 2016, 58, 1486-1499.

(77) Carrere, H.; Antonopoulou, G.; Affes, R.; Passos, F.; Battimelli, A.; Lyberatos, G.; Ferrer, I. Review of Feedstock Pretreatment Strategies for Improved Anaerobic Digestion: From Lab-Scale Research to Full-Scale Application. Bioresour. Technol. 2016, 199, 386-397.

(78) Li, H.; Chang, J.; Liu, P.; Fu, L.; Ding, D.; Lu, Y. Direct Interspecies Electron Transfer Accelerates Syntrophic Oxidation of Butyrate in Paddy Soil Enrichments. Environ. Microbiol. 2015, 17 (5), 1533-1547.

(79) Yan, W.; Shen, N.; Xiao, Y.; Chen, Y.; Sun, F.; Kumar Tyagi, V.; Zhou, Y. The Role of Conductive Materials in the Start-up Period of Thermophilic Anaerobic System. Bioresour. Technol. 2017, 239, 336344

(80) Zhao, Z.; Zhang, Y.; Woodard, T. L.; Nevin, K. P.; Lovley, D. R. Enhancing Syntrophic Metabolism in Up-Flow Anaerobic Sludge Blanket Reactors with Conductive Carbon Materials. Bioresour. Technol. 2015, 191, 140-145.

(81) Lei, Y.; Sun, D.; Dang, Y.; Chen, H.; Zhao, Z.; Zhang, Y.; Holmes, D. E. Stimulation of Methanogenesis in Anaerobic Digesters Treating Leachate from a Municipal Solid Waste Incineration Plant with Carbon Cloth. Bioresour. Technol. 2016, 222, 270-276.

(82) Zhao, Z.; Zhang, Y.; Holmes, D. E.; Dang, Y.; Woodard, T. L.; Nevin, K. P.; Lovley, D. R. Potential Enhancement of Direct Interspecies Electron Transfer for Syntrophic Metabolism of Propionate and Butyrate with Biochar in Up-Flow Anaerobic Sludge Blanket Reactors. Bioresour. Technol. 2016, 209, 148-156.

(83) Zhao, Z.; Li, Y.; Quan, X.; Zhang, Y. Towards Engineering Application: Potential Mechanism for Enhancing Anaerobic Digestion of Complex Organic Waste with Different Types of Conductive Materials. Water Res. 2017, 115, 266-277.

(84) Zhou, S.; Xu, J.; Yang, G.; Zhuang, L. Methanogenesis Affected by the Co-Occurrence of Iron(III) Oxides and Humic Substances. FEMS Microbiol. Ecol. 2014, 88 (1), 107-120.

(85) Yamada, C.; Kato, S.; Ueno, Y.; Ishii, M.; Igarashi, Y. Conductive Iron Oxides Accelerate Thermophilic Methanogenesis from Acetate and Propionate. J. Biosci. Bioeng. 2015, 119 (6), 678682.

(86) Baek, G.; Kim, J.; Lee, C. A Long-Term Study on the Effect of Magnetite Supplementation in Continuous Anaerobic Digestion of 
Dairy Effluent - Enhancement in Process Performance and Stability. Bioresour. Technol. 2016, 222, 344-354.

(87) Ambuchi, J. J.; Zhang, Z.; Shan, L.; Liang, D.; Zhang, P.; Feng, Y. Response of Anaerobic Granular Sludge to Iron Oxide Nanoparticles and Multi-Wall Carbon Nanotubes during Beet Sugar Industrial Wastewater Treatment. Water Res. 2017, 117, 87-94.

(88) Yin, Q.; Yang, S.; Wang, Z.; Xing, L.; Wu, G. Clarifying Electron Transfer and Metagenomic Analysis of Microbial Community in the Methane Production Process with the Addition of Ferroferric Oxide. Chem. Eng. J. 2018, 333, 216-225.

(89) Wang, T.; Zhang, D.; Dai, L.; Chen, Y.; Dai, X. Effects of Metal Nanoparticles on Methane Production from Waste-Activated Sludge and Microorganism Community Shift in Anaerobic Granular Sludge. Sci. Rep. 2016, 6, 25857.

(90) Suanon, F.; Sun, Q.; Li, M.; Cai, X.; Zhang, Y.; Yan, Y.; Yu, C. P. Application of Nanoscale Zero Valent Iron and Iron Powder during Sludge Anaerobic Digestion: Impact on Methane Yield and Pharmaceutical and Personal Care Products Degradation. J. Hazard. Mater. 2017, 321, 47-53.

(91) Ye, J.; Hu, A.; Ren, G.; Zhou, T.; Zhang, G.; Zhou, S. Red Mud Enhances Methanogenesis with the Simultaneous Improvement of Hydrolysis-Acidification and Electrical Conductivity. Bioresour. Technol. 2018, 247, 131-137.

(92) Li, Y.; Zhang, Y.; Yang, Y.; Quan, X.; Zhao, Z. Potentially Direct Interspecies Electron Transfer of Methanogenesis for Syntrophic Metabolism under Sulfate Reducing Conditions with Stainless Steel. Bioresour. Technol. 2017, 234, 303-309.

(93) Qiao, S.; Tian, T.; Qi, B.; Zhou, J. Methanogenesis from Wastewater Stimulated by Addition of Elemental Manganese. Sci. Rep. 2015, 5, 12732.

(94) Hu, Q.; Sun, D.; Ma, Y.; Qiu, B.; Guo, Z. Conductive Polyaniline Enhanced Methane Production from Anaerobic Wastewater Treatment. Polymer 2017, 120, 236-243.

(95) Tian, T.; Qiao, S.; Li, X.; Zhang, M.; Zhou, J. Nano-Graphene Induced Positive Effects on Methanogenesis in Anaerobic Digestion. Bioresour. Technol. 2016, 224, 41-47.

(96) Lin, R.; Cheng, J.; Zhang, J.; Zhou, J.; Cen, K.; Murphy, J. D. Boosting Biomethane Yield and Production Rate with Graphene: The Potential of Direct Interspecies Electron Transfer in Anaerobic Digestion. Bioresour. Technol. 2017, 239, 345-352.

(97) Li, L. L.; Tong, Z. H.; Fang, C. Y.; Chu, J.; Yu, H. Q. Response of Anaerobic Granular Sludge to Single-Wall Carbon Nanotube Exposure. Water Res. 2015, 70, 1-8.

(98) Zhang, S.; Chang, J.; Lin, C.; Pan, Y.; Cui, K.; Zhang, X.; Liang, P.; Huang, X. Enhancement of Methanogenesis via Direct Interspecies Electron Transfer between Geobacteraceae and Methanosaetaceae Conducted by Granular Activated Carbon. Bioresour. Technol. 2017.245132

(99) Yang, Y.; Zhang, Y.; Li, Z.; Zhao, Z.; Quan, X.; Zhao, Z. Adding Granular Activated Carbon into Anaerobic Sludge Digestion to Promote Methane Production and Sludge Decomposition. J. Cleaner Prod. 2017, 149, 1101-1108.

(100) Zhao, Z.; Zhang, Y.; Yu, Q.; Dang, Y.; Li, Y.; Quan, X. Communities Stimulated with Ethanol to Perform Direct Interspecies Electron Transfer for Syntrophic Metabolism of Propionate and Butyrate. Water Res. 2016, 102, 475-484.

(101) Xu, H.; Wang, C.; Yan, K.; Wu, J.; Zuo, J.; Wang, K. Anaerobic Granule-Based Biofilms Formation Reduces Propionate Accumulation under High H2 Partial Pressure Using Conductive Carbon Felt Particles. Bioresour. Technol. 2016, 216, 677-683.

(102) Zhao, Z.; Zhang, Y.; Li, Y.; Dang, Y.; Zhu, T.; Quan, X. Potentially Shifting from Interspecies Hydrogen Transfer to Direct Interspecies Electron Transfer for Syntrophic Metabolism to Resist Acidic Impact with Conductive Carbon Cloth. Chem. Eng. J. 2017, 313, $10-18$.

(103) Shen, Y.; Linville, J. L.; Urgun-Demirtas, M.; Schoene, R. P.; Snyder, S. W. Producing Pipeline-Quality Biomethane via Anaerobic Digestion of Sludge Amended with Corn Stover Biochar with in-Situ CO2 Removal. Appl. Energy 2015, 158, 300-309.
(104) Shen, L.; Zhao, Q.; Wu, X.; Li, X.; Li, Q.; Wang, Y. Interspecies Electron Transfer in Syntrophic Methanogenic Consortia: From Cultures to Bioreactors. Renewable Sustainable Energy Rev. 2016, 54, 1358-1367.

(105) Fujinawa, K.; Kouzuma, A.; Ueno, Y.; Watanabe, K. Conductive Carbon Nanomaterials Inhibit Methanogens. In Meeting of the International Society for Microbial Electrochemistry and Technology; Lisbon, 2017; p 220.

(106) Pasquini, L. M.; Hashmi, S. M.; Sommer, T. J.; Elimelech, M.; Zimmerman, J. B. Impact of Surface Functionalization on Bacterial Cytotoxicity of Single-Walled Carbon Nanotubes. Environ. Sci. Technol. 2012, 46 (11), 6297-6305.

(107) Frenzel, P.; Bosse, U.; Janssen, P. H. Rice Roots and Methanogenesis in a Paddy Soil: Ferric Iron as an Alternative Electron Acceptor in the Rooted Soil. Soil Biol. Biochem. 1999, 31 (3), 421430.

(108) Chidthaisong, A.; Conrad, R. Turnover of Glucose and Acetate Coupled to Reduction of Nitrate, Ferric Iron and Sulfate and to Methanogenesis in Anoxic Rice Field Soil. FEMS Microbiol. Ecol. 2000, 31 (1), 73-86.

(109) Jäckel, U.; Schnell, S. Suppression of Methane Emission from Rice Paddies by Ferric Iron Fertilization. Soil Biol. Biochem. 2000, 32 (11-12), 1811-1814.

(110) Lueders, T.; Friedrich, M. W. Effects of Amendment with Ferrihydrite and Gypsum on the Structure and Activity of Methanogenic Populations in Rice Field Soil. 2002, 68 (5), 24842494.

(111) Qu, D.; Ratering, S.; Schnell, S. Microbial Reduction of Weakly Crystalline Iron (III) Oxides and Suppression of Methanogenesis in Paddy Soil. Bull. Environ. Contam. Toxicol. 2004, 72 (6), $1172-1181$.

(112) Hori, T.; Müller, A.; Igarashi, Y.; Conrad, R.; Friedrich, M. W. Identification of Iron-Reducing Microorganisms in Anoxic Rice Paddy Soil by 13C-Acetate Probing. ISME J. 2010, 4 (2), 267-278.

(113) Achtnich, C.; Bak, F.; Conrad, R. Competition for Electron Donors among Nitrate Reducers, Ferric Iron Reducers, Sulfate Reducers, and Methanogens in Anoxic Paddy Soil. Biol. Fertil. Soils 1995, 19 (1), 65-72.

(114) Bond, D. R.; Lovley, D. R. Reduction of Fe(III) Oxide by Methanogens in the Presence and Absence of Extracellular Quinones. Environ. Microbiol. 2002, 4 (2), 115-124.

(115) Liu, D.; Dong Hailiang, H.; Bishop, M. E.; Wang, H.; Agrawal, A.; Tritschler, S.; Eberl, D. D.; Xie, S. Reduction of Structural Fe(III) in Nontronite by Methanogen Methanosarcina barkeri. Geochim. Cosmochim. Acta 2011, 75 (4), 1057-1071.

(116) Yamada, C.; Kato, S.; Ueno, Y.; Ishii, M.; Igarashi, Y. Inhibitory Effects of Ferrihydrite on a Thermophilic Methanogenic Community. Microbes Environ 2014, 29 (2), 227-230.

(117) Fetzer, S.; Conrad, R. Effect of Redox Potential on Methanogenesis by Methanosarcina Barkeri. Arch. Microbiol. 1993, 160 (2), 108-113.

(118) Hirano, S.; Matsumoto, N.; Morita, M.; Sasaki, K.; Ohmura, N. Electrochemical Control of Redox Potential Affects Methanogenesis of the Hydrogenotrophic Methanogen Methanothermobacter Thermautotrophicus. Lett. Appl. Microbiol. 2013, 56 (5), 315-321.

(119) Zhuang, L.; Xu, J.; Tang, J.; Zhou, S. Effect of Ferrihydrite Biomineralization on Methanogenesis in an Anaerobic Incubation from Paddy Soil. J. Geophys. Res.: Biogeosci. 2015, 120 (5), 876-886.

(120) Liu, Y.; Balkwill, D. L.; Henry, C. A.; Drake, G. R.; Boone, D. R. Characterization of the Anaerobic Propionate- Degrading Syntrophs Smithella Propionica. Int. J. Syst. Bacteriol. 1999, 49, $545-556$.

(121) De Vrieze, J.; Gildemyn, S.; Arends, J. B. A.; Vanwonterghem, I.; Verbeken, K.; Boon, N.; Verstraete, W.; Tyson, G. W.; Hennebel, T.; Rabaey, K. Biomass Retention on Electrodes Rather than Electrical Current Enhances Stability in Anaerobic Digestion. Water Res. 2014, 54, 211-221. 
(122) Lu, A. H.; Salabas, E. L.; Schüth, F. Magnetic Nanoparticles: Synthesis, Protection, Functionalization, and Application. Angew. Chem., Int. Ed. 2007, 46 (8), 1222-1244.

(123) Zobell, C. E. The Effect of Solid Surfaces upon Bacterial Activity. J. Bacteriol. 1943, 46 (1), 39-56.

(124) Kirchman, D. The Production of Bacteria Attached to Particles Suspended in a Freshwater Pond. Limnol. Oceanogr. 1983, 28 (5), 858-872.

(125) van Loosdrecht, M. C.; Lyklema, J.; Norde, W.; Zehnder, A. J. Influence of Interfaces on Microbial Activity. Microbiol. Rev. 1990, 54 (1), 75-87.

(126) Ammar, Y.; Swailes, D.; Bridgens, B.; Chen, J. Influence of Surface Roughness on the Initial Formation of Biofilm. Surf. Coat. Technol. 2015, 284, 410-416.

(127) Medilanski, E.; Kaufmann, K.; Wick, L. Y.; Wanner, O.; Harms, H. Influence of the Surface Topography of Stainless Steel on Bacterial Adhesion. Biofouling 2002, 18 (3), 193-203.

(128) Coman, V.; Kreibik, Ş. Layer Dielectrochromatographyunder External Alternating Current, LDEC. In Forced-Flow Layer Chromatography; Elsevier, 2016; pp 285-345.

(129) Habouzit, F.; Gévaudan, G.; Hamelin, J.; Steyer, J. P.; Bernet, N. Influence of Support Material Properties on the Potential Selection of Archaea during Initial Adhesion of a Methanogenic Consortium. Bioresour. Technol. 2011, 102 (5), 4054-4060.

(130) Roden, E. E.; Zachara, J. M. Microbial Reduction of Crystalline Iron(III) Oxides: Influence of Oxide Surface Area and Potential for Cell Growth. Environ. Sci. Technol. 1996, 30 (5), 16181628.

(131) Pereira, L.; Pereira, R.; Pereira, M. F. R.; van der Zee, F. P.; Cervantes, F. J.; Alves, M. M. Thermal Modification of Activated Carbon Surface Chemistry Improves Its Capacity as Redox Mediator for Azo Dye Reduction. J. Hazard. Mater. 2010, 183 (1), 931-939.

(132) Mezohegyi, G.; Kolodkin, A.; Castro, U. I.; Bengoa, C.; Stuber, F.; Font, J.; Fabregat, A.; Fortuny, A. Effective Anaerobic Decolorization of Azo Dye Acid Orange 7 in Continuous Upflow Packed-Bed Reactor Using Biological Activated Carbon System. Ind. Eng. Chem. Res. 2007, 46 (21), 6788-6792.

(133) Mezohegyi, G.; Bengoa, C.; Stuber, F.; Font, J.; Fabregat, A.; Fortuny, A. Novel Bioreactor Design for Decolourisation of Azo Dye Effluents. Chem. Eng. J. 2008, 143 (1), 293-298.

(134) Mezohegyi, G.; Gonçalves, F.; Órfão, J. J. M.; Fabregat, A.; Fortuny, A.; Font, J.; Bengoa, C.; Stuber, F. Tailored Activated Carbons as Catalysts in Biodecolourisation of Textile Azo Dyes. Appl. Catal., B 2010, 94 (1), 179-185.

(135) Pereira, R. A.; Salvador, A. F.; Dias, P.; Pereira, M. F. R.; Alves, M. M.; Pereira, L. Perspectives on Carbon Materials as Powerful Catalysts in Continuous Anaerobic Bioreactors. Water Res. 2016, 101, 441-447.

(136) van der Zee, Frank P.; Bisschops, I. A. E.; Lettinga, G.; Field, J. Activated Carbon as an Lectron Acceptor and Redox Mediator during the Anaerobic Biotransformation of Azo Dyes. Environ. Sci. Technol. 2003, 37 (2), 402-408.

(137) Amezquita-Garcia, H. J.; Razo-Flores, E.; Cervantes, F. J.; Rangel-Mendez, J. R. Activated Carbon Fibers as Redox Mediators for the Increased Reduction of Nitroaromatics. Carbon 2013, 55, 276284.

(138) Fu, H.; Zhu, D. Graphene Oxide-Facilitated Reduction of Nitrobenzene in Sulfide-Containing Aqueous Solutions. Environ. Sci. Technol. 2013, 47 (9), 4204-4210.

(139) Colunga, A.; Rangel-Mendez, J. R.; Celis, L. B.; Cervantes, F. J. Graphene Oxide as Electron Shuttle for Increased Redox Conversion of Contaminants under Methanogenic and SulfateReducing Conditions. Bioresour. Technol. 2015, 175, 309-314.

(140) Amezquita-Garcia, H. J.; Rangel-Mendez, J. R.; Cervantes, F. J.; Razo-Flores, E. Activated Carbon Fibers with Redox-Active Functionalities Improves the Continuous Anaerobic Biotransformation of 4-Nitrophenol. Chem. Eng. J. 2016, 286, 208-215.

(141) Pereira, L.; Pereira, R.; Pereira, M. F. R.; Alves, M. M. Effect of Different Carbon Materials as Electron Shuttles in the Anaerobic
Biotransformation of Nitroanilines. Biotechnol. Bioeng. 2016, 113 (6), 1194-1202.

(142) Oh, S. Y.; Son, J. G.; Chiu, P. C. Biochar-Mediated Reductive Transformation of Nitro Herbicides and Explosives. Environ. Toxicol. Chem. 2013, 32 (3), 501-508.

(143) Toral-Sánchez, E.; Ascacio Valdés, J. A.; Aguilar, C. N.; Cervantes, F. J.; Rangel-Mendez, J. R. Role of the Intrinsic Properties of Partially Reduced Graphene Oxides on the Chemical Transformation of Iopromide. Carbon 2016, 99, 456-465.

(144) Toral-Sánchez, E.; Rangel-Mendez, J. R.; Ascacio Valdés, J. A.; Aguilar, C. N.; Cervantes, F. J. Tailoring Partially Reduced Graphene Oxide as Redox Mediator for Enhanced Biotransformation of Iopromide under Methanogenic and Sulfate-Reducing Conditions. Bioresour. Technol. 2017, 223, 269-276.

(145) Baek, G.; Jung, H.; Kim, J.; Lee, C. A Long-Term Study on the Effect of Magnetite Supplementation in Continuous Anaerobic Digestion of Dairy Effluent - Magnetic Separation and Recycling of Magnetite. Bioresour. Technol. 2017, 241, 830-840.

(146) Lü, F.; Luo, C.; Shao, L.; He, P. Biochar Alleviates Combined Stress of Ammonium and Acids by Firstly Enriching Methanosaeta and then Methanosarcina. Water Res. 2016, 90, 34-43.

(147) Luo, C.; Lü, F.; Shao, L.; He, P. Application of EcoCompatible Biochar in Anaerobic Digestion to Relieve Acid Stress and Promote the Selective Colonization of Functional Microbes. Water Res. 2015, 68, 710-718. 